\title{
Gender and Development: A Study of Feminist Theories
}

\author{
Farhana Haque (Corresponding author) \\ Academy of Brunei Studies, University of Brunei Darussalam \\ Brunei \\ E-mail: dhak_121@yahoo.com
}

Received: July 18, 2020 Accepted: August 30, 2020 Published: September 23, 2020

doi:10.5296/ijch.v7i2.17734 URL: https://doi.org/10.5296/ijch.v7i2.17734

\begin{abstract}
The term feminism derived from the notion to establish women's right equal like men. It refers to the ideology that men and women should be treated equally both in the sections of politics and morality. Feminism means to create a scope to women to raise their voice against men regarding the matter of equality and as a result feminism does frequently linked towards different types of motions since last two centuries and performed to execute the concept of parity through implanting it throughout the culture. There are several other opinions and ideologies by different feminists regarding the term equality. The individual feminists said equality means equal treatment and that should be under the laws about homage the person and possession like the entire human beings without paying attention towards the secondary characteristics like sex, race, ethnicity. The school of feminism which is radical feminism. According to them parity means socioeconomic parity where power and wealth should be re-established by law through the society. Therefore from the historical perspectives advantages of men become deleted.
\end{abstract}

\section{Keywords: Gender development, Feminism, Feminist theories, Men and women}

\section{Introduction}

From the previous history we can see that in the western society in 18th century feminism established as a challenge against the laws and practices that women's task is to hold the subordinate role in front of men. Olympe de Gouges and Mary Wollstonecraft who embossed their voice against that rule. In 1791, the French playwright and journalist De Gouges released the proclamation of rights about women and the citizen in response to the popular proclamation of the rights about men and the citizen of 1789. In her proclamation she complained about banning women from citizenship hence did dispute about the issue of equality between the two sexes. As a British classical liberal feminist Mary Wollstonecraft 
was known. She also rejoined to the French revolution. From that response she wrote the pamphlet vindication of the rights of men (1790), for defending the plans of revolution which did happen by attacking the British statesman Edmund Burke. In 1792 she did defense about the rights of women. After that she disputed that women are same as men and only considered lesser because of their low standard of education that engage them towards the domestic chores. Feminism actually proclaimed about boarder demand regarding the rights which need to be equally recognized by saying that women to be educated for thinking independently. Western feminism thus was originated through the declaration about men and women's equal rights as moral and political sections in life. Apart from British feminism, American feminism emerged from a contrasting position of historical conditions. Specifically in 1830s abolitionist movement popped out. This movement was the radical anti-slavery movement which was requested the hasty ending to slavery on the basis of the concept like every man was a self-owner, which indicates every man has moral control over his own body. In various ways abolitionism encouraged feminism. As a radical movement it was very efficient where women were acted as leaders and also were inspired to talk from public platform and also the presence of mixed spectators (men and women). Female abolitionists came from Quaker backgrounds in a several ways. They were given extra power on education and equality than other common population. But they appeared to be working for men's self-freehold and not for women. And soon they felt uncomfortable with one characteristics of abolitionism. William Lloyd Garrison, arrived to champion women's rights and discussed about the discomfort zone of the female abolitionism. The drawback of 19th century was significant where women were deprived for entering to any agreements without her husband's permission. So by that way women lost their rights on property and future earnings upon marriage. Besides women children were also legally directed by the father where women were imprisoned by the husbands and other male members. As a feminist Sarah Grimke's popular pamphlet, Letters on the Equality of the Sexes and the Condition of Woman (1837), measured the constitutions of male governing slaves with the governing women. So we can understand that feminist requests emphasized on removing legal obstructions for women. And also gain the same rights to person and property like men observed. In 1840 the central moment came when American female representatives locked from sitting in the assembly. After that conference, two women (Lucretia Mott and Elizabeth Cady Stanton) among others were infuriated when they returned home. Soon after that they formed the 1848 Seneca Falls Convention for exploring about women's rights and conscripted the proclamation of their point of views. It was the most popular feminist record which rephrased the proclamation of freedom to claim woman's independence from man's threat. A woman's voting rights was also initiated in that declaration. In 1920th the outcome of 19th amendment laws of mainstream American feminism aimed about joining the vote for women with Stanton and Susan B. Apart from them, other feminists were operative in three different area such as social (especially labor) reform, generative rights, and teaching. They have focused their broader movements through either individuals or female voices. In Britain there happened. Before the voting system was widened "Suffragettes" that campaigned for universal suffrage. And in 1918 to single women whose age was around 30 vote was extended to them as well as to all adults over 21 years of age in 1928. But in America and Britain after acquiring the 
rights to vote for women that system showed some central lacking to motivate the movement and the individual women raised their voice out for women's rights. Nonetheless, feminism refers to the issue of self-consciousness and independence as the movement but that movement effectively disappeared from America up to 1960s. As with abolitionism, Second Wave feminism appeared from discontent with the performance towards women within a frontier movement. This re-establishment sprang from left-wing or liberal beliefs.

In 1950s, the Second Wave feminism's call for women's rights resounded with innumerable women who were scratched at the sexual and social limitation which has included chastity before marriage, the beliefs that they should think on their domestic works rather than a career, as well as got prohibition against children out of marriage. Helen Gurley Brown wrote Sex and the Single Girl (1962), which has indicated the pop up sexuality that followed both the emergence of feminism and the new chance of productive birth control pill. Women requested same rights and fair treatment within the undeniable system. Second wave feminism is the movement where their one of the major aims were to establish positive actions through which women should be added in significant figures within verified institutions such as universities. The U.S. laws focused to give the guarantee about equal rights under the constitution regardless of sex. For liberal feminism equal right amendment (ERA) became the vital issue. When the ERA's time limit for outcome expired in 1979, liberal feminism has proved this as failure. In the early $1080 \mathrm{~s}$, radical feminism became rationally authoritative. In past radical feminism also known as gender feminism that performed like a revolutionary, minority voice within the second wave feminism. In the section of radical feminism, patriarchy society which is the amalgamation of white male culture and capitalism through men as a class supposed to oppress women as a class. Radical feminism's policy is to establish the concept of political fidelity. For example, government funds are generally distributed to the schemes which assist the declaration of actual sexual norms inside of the workplace and on campus. For the time being laws and policies against incorrect norms (for example, sexist harassing) which make difficult to such declaration frequently through exorbitant lawsuits. Feminist in ifeminism stood against the punishment of speech which was intended to prevent harassment and they faithfully defended that freedom of expression especially speech on which the society disapprove. Above all by censoring laws that has been utilized to stop abolitionist feminists from speaking out on both women's rights and slavery. According to the feminist history, censorship has suffocated conversations about the controversial topics such as birth control. Hence it's known that, free speech was pivotal to the evolution of feminism also the welfare of women.

Beliefs about the class conflict dormant the political accuracy as well as moves to feminism's discrete roots. Political accuracy split up the society into distinct classes split up the society into recognizable classes explained by the attributes such as gender and race. The classes are seemed to hold various hostile political benefits. Consequently, government's involvement is important to save as well as its gimmick disadvantaged classes for ensuring exact allocation of wealth and power throughout society that appears. To sum up, some classes gain governmental advantages to the disadvantage of other classes.

Individualist feminism counsels ending of all classes to the contrary which is under law so 
that every discrete can get equal rights, equal claim to person and property, regardless of aspects such as gender or race. The actual part of government is to remove the advantage and shield the rights of discrete men and women equally.

Different ideological approach such as equity feminism targets towards parity under existing organizations without necessarily changing the current system to show the natural rights of individuals. Ecofeminism refers to get linked with the male dominance upon women to destroy the surroundings to focuses on the duty of women that must play in links about male domination of women to the destruction of the habitat and focuses on the role women must play in protecting nature. In Western countries most inequalities happen under the law and within the culture which is disrupt to create a chance to both males and females for facing the same fundamental options. Certainly the advantages that women got accepted through some policies such as positive action. Thus, both individualist and equity feminism claim about exclusion of advantages for women in order to gain true equality. Furthermore, emergence of counterintuitive schools of feminism, such as conservative feminism promotes the traditional family and conservative values, and acted to unsharpened the historical aims and goals of feminism.

Apart from Western countries such as Africa and Arab nations, women are frequently undergo second class citizenship and universal violation of their inherent rights. The burqa (Hijab) got the symbol of the oppression of such women, but it is also refers to the division between Western and non- Western feminists. Veils are one of the most significant sign of Muslim women and women are often forced to wear mostly by the Taliban in Afghanistan, which is hateful to Western feminists. But many of the non- Western correlative argue that wearing veils or burqa or adopting other allegedly anti-female practices of Islam which should be free choice and should be respected. As radical feminism indicates progressively by global institutions, especially through the United Nations. It's actually unclear beliefs and objectives will harmonize with the deep cultural differences that confront among women.

\section{Distinction about Sex and Gender for Exploring Males and Females Issues of Having Equal Right according to Different Feminist Theorists}

Women are considered as submissive in front of men both at home and in the society. In a male dominated society it is said that, women's mental and physical effects are less than men to maintain the power of outside worlds like men. In addition, it can be said that the patriarchal society forced women to stay and work in their domestic periphery and think its better suited for them. According to the Postindustrial society, sex and gender are not significant regarding the difference between sex and gender. Therefore, this refers difficulty of women's child birth and its considerably below important regarding the dissimilarity between sex and gender and therefore this refers handicap to women of handicap to women of child birth is considerably reduced with the presence of contraception as well as the pain relief in the time of labor. Ann Oakley's talked about gender in her path finding text, Sex, Gender and Society (1972) which possibly did set the ground for further investigation about the creation of gender. Oakley argued about gender differences after saying that, since women are appointed to do the household works established by the patriarchal society and if there we 
need to play with those roles of women then we have discovered that history. Hence that would be disrespectful which we needed to eliminate this type of thinking long ago. In the book of 'The Second Sex' by Simone De Beauvoir, she explained about how women and men got their rights through the theory of performativity. She said, 'one is not born, but rather becomes a woman' (De Beauvoir 1972:295). So Simone De Beauvoir's opinion about gender differences are against hierarchical system where the ideologies of males are invariably the favored norm and feminine one that placed as 'other'. According to Simone De Beauvoir the advancement was masculine and it's indicated as deeply, therefore women as eunuch or continual disorders. In 1970s the mass of feminists hold the idea of gender as construct. So in that same year youth culture endorsed for the passion of' unisex clothing', but here in this point Shulamith Firestone was exception, she said in " The Dialectic Sex (1970s) and criticized about patriarchal ideologies regarding women that has been exploited women's biological magnitude to replicate as their crucial frailty. According to Firestone, biological difference of women can't be any problem but it could be their individual distinction or special quality instead of thinking that as the drawback of women. as she remarked, oppression can be decreased by women through adopting the technologies to break down the traditional child give birth process and also she said to increase the use of different mechanisms to set themselves free from the difficulties of child birth like use of contraception, restore women's eggs etc. Like De Beauvoir, Firestone was the conservative feminist, her notion was to diminish the living connection between mothers and children. She wished to establish the same collective groups such as monogamy and nuclear family are things of past. Scarce numbers of feminists were supportive regarding the view of Firestone's opinion of child birth and the mother-child bond because of different mechanism, hence it was effective in the past as well as still it's happening in the hands of men. Cultural feminists then interrogated whether all main dissimilarities are an affect to civilization rather than biology or not. They preferred to gain and observe the roles of mothering as proof of women's inborn constitution to the nurturance and pacifisms as well as would be unwilling to surrender to that technological things by Firestone even if they could. So cultural feminists are against Firestone's theory. For Oakley the conceptualization of gender is main foundation of second wave feminism. Oakley remarked, there is constant slippage between sex and gender. Recent research on sex and gender indicates that feminism depends on polarization of the sex/gender discrimination. They disclosed the meanings attached to sex differences are socially formatted and variable. Sex is consequence of biological facts within our own cultural and historical contexts. Transgender is the example and these people characterized their perception of something being wrong with them as being confined in the wrong body. So Moira Gatens indicated 'that the male body and the female body have quite different social value and significance cannot help but have a marked effect on male and female consciousness' (Gatens. Moira, 1996:9). She further discussed about certain bodily events and they happen to one sex and she cited the example of menstruation. In other ways, she also did indicate male body is spread in our culture with the mythology of supremacy. Another extreme feminist named Judith Butler was against the supremacy of male body. According to her, 'gender introduces the notion of performativity'. Her concept of gender is possibly the most desperate of all. She explained about Foucauldian model, and declared that 
all identity categories ' are in fact the effects of institution, practices, discourses with multiple and diffuse points of origin' (Butler 1999: ix). Butler further presented radical interruption between sexed bodies and culturally formatted genders. Assuming for the moment the firmness of binary sex, it does not follow that the formation of 'men' will accumulate specially to the bodies of males or that 'women' will explain only female bodies. This resemble questioned the whole way we thought for setting the definition about men and women's identity. So we can say that, the idea of gender as performance indicates the level of free play with gender classifications that we enter into socially. In this concept there is no obligatory heterosexuality. Butler's most radical deconstruction of the sex/gender distinction was enveloped in particular by queer theorists and third wave feminism.

\section{Differences between Women and Men}

Opinions regarding differences between women remain split into parts like in one side differences. Traditionally women assume about shared worries that is less credible where one the other sides there is the question about the possibilities that differences create between women to strengthen associations by demonstrating the experience and potential of women to achieve something great. According to Pilcher \& Whelehan, "the notion of sisterhood with global reach was compelling and suitable optimistic" (Pilcher \& Whelehan, 2004, P.28). But when the idea of sisterhood was developed then the distinctness between women, ethnic group, order, family, occurrences, sexual orientation which were believed as a shaping experience. Now apart from distinctness between women, ethnic group, order, family, occurrences, sexual orientation but when it's time to refer the sexual differences there are waves. Therefore Nancy Cott described 'difference' and 'sameness' are the matter of disputes in feminism and also proclaimed that women got the same cognitive and logical standards as men have and also women having special attributes. This refers to some of the intense meanings about women. The explanation of women as sex/class that has provided the major subscription of current feminist theory. And this was dragged in two routes to the removal of gender roles (sameness argument) as well as towards the valorization of women. It can be said that in our recently advanced society corporeal dissimilarity between male and female should not harmfully effect their aptness to receive roles, yet it is essential to admit that inherent effect regarding the identity of women. For example women do give birth of child, hence it is occasional need for them to get different treatment. On 1980s witnessed about the advantage which present the sexual difference in the theory of feminism and debunked the declaration for sisterhood.

So in 1980s sexual difference was prominent than sisterhood. Ethnological, tribal and sexual variety among women were more emphasized matter in a significant ways, hence also emphasize about women difference from men. The second wave feminism was categorized by Lynne Segal and others which was based on the contradiction which indicates to the biological differences can create any salient impact towards the second capabilities of men and women. Segal's propensity to display women is to express the attribute of women like a pacifist, naturist therefore usually more considerate which is a sign about taking control with interrogations of the violence of men and as well as their and aggressive notions. In 1980s there has been raised another concept in feminism which was known as cultural feminism 
that was growing hegemony and subsumed radical feminism. Echols observed, "Cultural feminism with its insistence upon women's essential sameness to each other and their fundamental difference from men seemed towards many to unify a movement that by 1973 was highly schismatic" (Echols, 1989:244). This cultural feminism was the response to backlash according to Echols and the conservative rejection of 1960s' radicalism. "The difference and sameness debate re-emerged in the late 1980s and coincided with more feminists embracing post- structuralism and post-modern ideas" (Pilcher \& Whelehan, 2004, P.29). So the theorists remarked that, for achieving impartiality on the basis of likeness means to incorporate females into male-oriented structures which accept men's skills and criterion to provide the meaning about equal being regarded as women. And they should penetrate into male realm. According to Anne Phillips, "women can say they want to be treated the same but this means being treated as if they were men; or they can demand laws that are specific to their needs but this means being compensated for their lesser abilities or role. The fact is that the norm is already sexually specific...[w]e should think rather of a plurality of many differences, so that equality becomes compatible with diversity instead of forcing us into the self-same mould" (Phillips in Barrett and Phillips 1992:20). The post-structuralisms this means binary opposition and sameness. So we can say human culture can only be recognized in relation to one another and how they function within a massive order. So in this way it can be said that, civilization, historical context, tradition and the formation of gender have influence on human experience and that us why body and mind can't be divided but the feelings of mind has impact on human body and these are interrelated. Yet Bryson said that obviously society does treat biological differences which is highly significant and noticeable. As we know every individual human beings are classified from the time of birth as boy or girl therefore the prediction of whole gender got portrayed on this initial sex contrast. Sawicki remarked, "We need to be able to see ourselves as women if we are to resist our current constructions as women" (Sawicki 1999:49). This is important for women to give value to the ideas about difference. She said, women need to pay attention to difference or show interest to homogenies experience and they need not think difference as obstacle. Again Sawicki suggested that, "difference can be a resource in so far as it enables us to multiply the sources of resistance to the many relations of domination that circulate through the social field. If there is no central locus of power, then neither is there a central locus of resistance. Moreover if we redefine our differences, discover new ways of understanding ourselves and each other, then our differences are less likely to be used against us" (Sawicki 1999:45).

\section{Domestic Division of Labor between Male and Female Members}

The distribution of responsibilities between family members, basically male and female family members means domestic division of labor. Historically and currently as we know in most of the societies are occupied with many Western industries therefore their specific and assigned responsibilities imposed upon males and females. Thus in those responsibilities and differences are present among them. Since industrialization, men's primary responsibility was to provide financial support by going outside of home to get wage, on the other hands, women's primary responsibility was to manage the household chores and other responsible works such as cooking, cleaning dishes in the kitchen and do the work of laundry, shopping, 
feeding and caring of children. And these types of domestic labor was undertaken by women and also they are not getting any payment for that. Though they do prefer those duties to complete regularly within the home. The idea of household chores which is known as domestic division of labor that labor came to the lime light in academic premises in the 970s. According to Pilcher \& Whelehan, "what women do within the home, although unpaid, is 'work' or 'labor' in other words, a form of productive activity like men's waged labor" (Pilcher \& Whelehan, 2004, P.31). Pilcher and Whelehan again remarked, "unpaid house work and caring work replenish labor power on a daily and generation basis, and in this way contributing to the production of surplus value, sustain the capitalist dynamic" (Pilcher \& Whelehan, 2004, P. 31).

Other theorists said, there is a connection between capitalism and patriarchy. Women's wages are lower in their work place. In most of the societies we can see that most of the women are dependent on men, and eventually they are supposed to marry whether they are independent physically, mentally or economically. Therefore the traditional task of a married woman centered towards performing household works for their husbands and children. The domestic division of labor actually play the role of weakening women's potentiality in the labor market. Consequently the hierarchical domestic division of labor is sustained by the labor market and vice versa. The origination of patriarchal system has been established before men used to hold the entire power over women and children in family. So after ruling women at home they cultivated the mechanism of hierarchical organization which is like the structure of capitalism. Pilcher and Whelehan declared, "Job segregation invariably means that it is men who hold the jobs with greater material rewards, not least relatively high wages compared to women" (Pilcher \& Whelehan, 2004, P. 31). "Vicious circle of disadvantage for women" (Pilcher \& Whelehan). According to Leonard and Delphy "women's oppression is directly beneficial to men and perhaps only indirectly beneficial to capitalism" (Delphy and Leonard 1992:29). They again asserted in favor of women and gave statement about women's contribution for men. "Practical, emotional, sexual, procreative and symbolic and symbolic work done by women for men within family relationships" (Delphy and Leonard 1992:23). Thus it is to be said that, women's contribution does take place within a domestic periphery or patriarchal area. Men are taking advantages from women since their domestic works are unpaid and men get benefit from that directly. Also they are not helping women or not taking responsibilities for performing that never ending domestic work. For this attitude they are getting advantage in the labor market. During the 20th century to the era of 1060s, British census data showed about women acquired less than one third of their total paid in labor force. Twomey said, "After the 1960s and 1970s, however, women's representation in the labor force began to rise, and by 2001 women were 44 per cent of the working age labor force" (Twomey 2002). The difference happened regarding domestic division of labor during the years 1960s and 1970s. In these years studies on family life did exhibit that domestic division of labor was started to be equal. For example more married women became involved in paid work both at home and as well as in the outside of home, while it has to be imagined that more men were supposed to perform household work and caring work within the home. Domestic division of labor, later revealed that in spite of women's engagement in paid work, though they endure bound to complete massive unpaid housework and caring Sullivan 
discovered in 1997, women were engaged with the pile of household work. Also men's participation in domestic work was also great in number where there was a considering significant increase of egalitarian couple among full time employed. So this 1997 was the positive year for getting proper rights to women in the issue of domestic division of labor. Over time men were helpful and taking part in household chores even though they also described about themselves regarding being responsible for doing plenty of works. Yet there was happening some positive attitudes in men for understanding women's hardship but the conventional model of the domestic division of labor became absolutely resilient. Some study propose that when both the women and men affirm full time paid work, then the resolution progressively favored for paying someone (usually a women) to do the household work. Because of endurance there was happened slower transformation in the conventional domestic division of labor. Strong research behind this drawbacks of women's domestic division of labor revealed that it's only happened by the reasons of their lack of economic power than their male partners. And this thing occurred by the reason of the issue which is based on gender segregation in paid work as well as belief about gender roles. So the perception of fairness means usually connected with conventional parts of women's work within home and it means fairness has to be centered on women's work at home, for example, feeding and taking care of children, washing cloths and dishes, cooking shopping. And when men do share their female partners' work and help them then for women that's called fairness. So in this way further significant and considerable transformation in the domestic division of labor will happen very slowly.

\section{The Conceptualization of Binary System for Women and Men}

According to feminist theorists, men's power and the state of official and unofficial behaviors become recognized by evaluating and regulating women. There is another problem regarding the behavioral standards to give properly balanced rights between men and women. For example instead of having single standard of behavior there exist binary where one is for men and other is for women. Androcentric is the system of civilization where binary system often give benefit, therefore applicable for men than women. Feminists argued about giving the same right such as citizenship rights like men, formal and legal quality for which they are striving for. That is why feminists have been concerned about the actuality of double standards. The idea of binary system was used in the clarification about the aging process. As men and women grow older, they become evaluated by different ways, as a result this creates privileges for older men. Women's qualities and attitudes get valued especially because of their youthful physical beauty, attraction and menaced by growing older. Also in society we know that men's value and dignity depends on their economic stability more than their outer appearance. The signs of aging in men are less heavily punished than they are in women. For men wrinkles and gray hair got appraise as a sign of good skills, as well as experiences and therefore known as distinct. But on the other hands, women are strongly encourage to hide the marks of aging on their faces and their bodies for unveiled the vigorous enchantment but threated by growing older. Men's value depends less on how they look and more on what they hold as a superior beings. Especially in the sector of economy. Hence it is quite vivid for exposing the issue of double standard, the aging process is one of the vital points. In society 
the ingrained belief about women's sign of aging on faces and bodies are negative, while on the other hands men's sign of aging on their faces and bodies are the sign of experience and intellect.

\section{The Universal Conviction of Parity about Women and Men}

Equality refers towards the state of sameness particularly inside the areas in social areas and political rights. In gender studies there we got some debate regarding equality or to become same. In western societies historically it has been discovered that men used to have superior social authoritative power both in legal and political parts of life than women. In Britain during the late 19th and 20th centuries, the feminists did the campaigned for establishing and expanding women's rights and advantages. For instance, in the fields of education, property, employment and the rights to cast vote same as men. In late 20th a scope to create constitution took place in order to enable it as easy for both the men and women via the banning of discriminatory practice. Therefore the dispute about the meaning of parity stayed like long-standing and on-going. The tension remained in the middle of British feminists in the 1920s and 1930s and this was proved as the problematic status of the concept of equality which leads to the tension towards the area of feminism. In the periods between 1920s and 1930s, there emerged one new feminists group who tried to provide special initiatives for women such as family endowment or help them after giving funding, also they attempted to provide the awareness of birth control. Finally they strived to create employment legislation for women. There were much tension for re-orientating women away from the domain of family which take to achieve parity with males in public sphere, when they needed to do concentrate to fix the privileges for women. For establishing those equal rights, feminists did introduce the movement for protecting rules by suggesting a basic difference for both men and women. Banks remarked that, it was women who got some drawbacks, "but also female weakness and dependence and to this extent at least female inferiority" (Banks 1981: 115). However he tried to say about the concept of female's weakness and the quality to depend on males which actually made them inferior. In the late 19th century and early 20th century the British feminists who did work on equal rights and concerned. Whether women needs equal rights like men by identifying the segments of unequal behaviors and annihilation via legal form or not. For example they argued for the term 'strict equality' which was happened between men and women in the area of labor market, because gender parity will not be achieved if there is no parity in the sectors of domestic labor and caring works between men and women.

William raised questions about gender equality in the sector of military for women. Therefore said that, what would be the roles of women in that military combat area. Pilcher and Whelehan wrote about William's questions in their book. "Women should not be exempt from combat roles, because this represents special treatment for women, and so allows the state to 'mark off' women as different in other ways" (Pilcher \& Whelehan, 2004, P.39). We can now say that parity in gender should not achieved or recognized through social value and the rights in society whereas it should be gained by gender neutrality. The goal to achieve gender equality should be established through the acceptance about the groups of minority (women) also their values, organizations and the way of life of the superior groups (men). If 
we want to overcome the different perspectives then we have to give recognition and also have to give value to the places where women are prominent and therefore different than men. For example, Irigaray, as a post structuralism said, women's understandings, their ideas about culture, bodily things and sexual experiences from men are acknowledged and valorized. Apart from Irigaray, other theorists said, especially Gilligan (1982) argued about women's distinguished ethics that requires equality which is gender-differentiated. Ruddick (1997) then suggested that, if we want to eliminate or reduce the issue of gender- differentiation then we have to value feminine qualities and make it as the center and also need to replace masculine values. The theorists about difference are critical to present the equality strategies. According to their opinions masculinity is the standard against women who are judged. Therefore through masculinity, femininity is settled differently, hence surpassed to establish parity to be gained. In society there are some certain groups who always give explanation about the continuation of models of social inequality. Thus the application of differentiation which is more robust and ruling. Among three perspectives, the third panorama in the sector of parity discussion imply beyond the division that portrayed by the previous two perspectives. There is another critic group which is diversity theorists. They criticized for the ideas about equality and difference. But "equality" perspectives deficit to identify the socially formed and the male domination which is the criterion of evaluation that considered as relevant to social incorporation. For gender-differentiated theorists, the aim was composed to the concept of gender-differentiated citizenship, where women's duties and experiences in the domestic areas are recognized and apprised. According to Lister both aims are twisted through their dormant dichotomous ideologies that leads to the political and theoretical dead-end. Consequently, diversity theorists declared equality and difference are exclusively opposites. To Lister who was a diversity theorists, he said, 'equality and difference are not incompatible; they only become so equality is understood to mean sameness' (Lister 1997:96). Iris Mason Young (1990) argued about equality. Young argued that, the "concept of equality needs to be re-conceptualized". In what Young tried to explain the diplomacy of difference, he observed that group differences are not neutralized or outstripped. As stated by Young, differences happen naturally by different social and cultural groups. So in this point we can't see it as negatively but we can see variation there. By the concept of Squires regarding differences, In order to explain the globally prepared what we call 'neutral' equality policies, Squires said, "that most clearly characterizes the present moment of gender theorizing" (Squires 1999:116).

\section{The Importance of Family to Evaluate Equality between Women and Men}

Feminist knowledge became developed and enlightened through 1970s while the term 'family' known as the dominant issue. Many people thinks that family is the pivotal site of women's maltreatment. In the sphere of family women gets unnoticed by the male members such as fathers, husbands, brothers, and their rule become or turned as the primitive patriarchal law. This very patriarchal society consider the issue of romantic love as home. According to feminists' theorists, family can be viewed in two ways. Family consider firstly as a social positioning, therefore it is subject to shift to the historical arrangement by definition but situated principally on the basis of close harmony. Secondly family can be 
defined via ideology which is internalized by everyone. Here one theory permit us to focus about families about how it actually been arranged, in any given historical and in any given cultural structure. From our family we know about gender difference, generally from our parents and siblings. On the other sides, morality and normality we learn from school. As Freud discussed about family very vividly. He remarked, family is also the place from where we get mental illness and as well as we get affected by extreme fear about anything like phobia. So it could be well or good ways to live or disturbed. Therefore we can say that, a happy family life can deliver the separate beings a long lasting happiness against the periods of isolation in public and professional life. In a negative sense, most of the sexual abuse happens inside the family as well as the victims become murdered by someone who are close to. Honoring to the feminists persuasions, preservation of the nuclear family was draining as well as it presents the tiresome, nonexistent of spiritual and more to the point, financial rewards. Also, this is useless for every family unit to do household works such as laundry, cooking and cleaning kind of stuffs for the minor group of people on a regular basis. The suggestion of feminists about domestic labor with women roles is to disaggregate domestic labor from women's life or they asked to give them rewarded for doing domestic labor in a family. But later the movement called remuneration for household chores became unwanted because there was the threat of connecting housework with homework. Since it was tried by the feminists and they did compare the work which has been done inside of home without any payment while on the other hands, the work that has been performed to pay for men in the workplace. Therefore it showed as the example of unjustness and the conventional social role of mother and wife. Difficulties happens upon women in most cases, because of the financial reason. Since men are expected to earn family wage. Therefore divorce rates increase and there are more evidence of single mothers. So it is need to give equal rights to single mothers like bread winners. Feminists became silently dissected over the issue of family during the years of 1980s and 1990s. But for the black women the scenario is different and they were deprived from their essential status in the home. Bell Hooks pointed out about this issue about black women, "they chose to see the independence, will power, and initiative of black women as an attack on the masculinity of black men...they argued that women's performance of any active role in family life both as mothers and providers had deprived black men of their patriarchal status in the home" (Hooks 1982:75-6). About the white feminists, Patricia Hill Collins discussed about and she talked of the African-American wider existence and family of other mothers. "Women who assist blood mothers by sharing mothering responsibilities” (Collins: 1990:119). Collins' dispute wasn't confined within Western family which doesn't match in all skills, according to her, the white feminists can acquire knowledge from the feeling of community called-African-American women and they can also get it easier than others for identifying connection which is the key method of knowing. They can be motivated to do so by a black women's custom and practice of sisterhood at the same time. Women become dispirit within their families and then again turn as the victims of domestic violence, and prevent themselves from the interrogation about actual formation of transforming the construction of family across cultures. 


\section{Important Issue of Patriarchy in the Process of Gender Development}

Preciously patriarchy refers to the ruling power of men or dictate by the leader of men in a social unit, for example a family, or dynasty. According to society, patriarchy is a person (male) who is the social elder special for younger men, women and children. Feminist writers used this idea to refer the discriminatory of masculine supremacy over women during the early 20th century. So in gender studies we can say patriarchy or patriarchal society become the most salient and fundamental concept. Patriarchy do lead one of the leading concepts among other concepts for exploring women's subordination in a male society. Among three important theories, patriarchy is the central concept. Those three concepts are, "radical feminist", "Marxist feminist", and "dual system". In radical feminism, the feminists do investigate the idea of patriarchy which is considered as the main and basic social division in society, also we can say in radical feminist analysis, the institution of family got the key importance via which men's supremacy got acquired. About patriarchy other feminists gave description about how men got the authority of women's body. For Firestone, the biological thing between males and females which got the most importance, she said, inequalities between men and women happen because of the biological reasons with different reproductive potentiality of women that is significantly salient. Again in other radical feminist critics, it is masculine authority over women's bodies by sexuality and other types of male brutality in the form of rape which is considered as being of key importance. Marxist feminists said about other concept to analyze the central concept of 'patriarchy'. So here in this zone, Marxist feminists says that, patriarchy originated from the ideologies of the capitalist economic system, it needs advantages from women's unsettled labor at home. Gender inequality also identify by the concept of class inequality. According to Barrett, "class inequality is argued to be the central feature in society and is seen to determine gender inequality" (Barrett 1988). Basically two systems got theoretical priority by the third grouping of feminist perspectives. Capitalism and patriarchy. Dual system theory represent the amalgamation of Marxist and radical feminist explanation about gender relations. In Marxist theories, dual motion of system can be seen to present or over emphasis the issues of class and capitalism. While on the other hands, in radical feminist theories dual system approach can be seen to present or over emphasis capitalism and patriarchy/biology. Honoring to Hartmann (1979), dual systems theory such as the theories of capitalism and patriarchy have been considered as independent, mutually accommodating method of subjugation by which both methods (capitalism and patriarchy) got structured and receive aid from women. For understanding the idea of patriarchy in a clear ways, four concepts of patriarchy are there, such as ahistoricism which means the abortion to admit the historical difference in gender relations, secondly, reductionism, which means minimizing and clarification of patriarchy within one or two factors such as biology or capitalism or the family. Thirdly, conceptualism which occur only between males and females. Since to realize the idea of patriarchy fully it is salient to realize about the relationship between men and women. At last, universalism which means failing to recognize cultural variations. Now it is again significant to know what the black feminist critics said about patriarchy. Basically patriarchy is failed to examine or theorize racism, and which is flawed and incomplete. Walby (1990) remarked, it is possible to vanquish the earlier complications about 
reductionism, ahistoricism, universalism and the propensity to lose agency in social and historical process. She then detected six structures of patriarchy. Such as household production, paid work, the state, male violence, sexuality, culture. So above formations can apprehend the depth of pervasiveness, linkage of women's subordination. Walby's theory of patriarchy also empower the rebuild of historical time. She said, during the 20th century, male domination got transformed from the private form to public areas. Since private patriarchy is formed with family, the household also involves the individual women. In this form women are confined within the household works and as well as they have limited access to participate in public life. On the other hands, in public patriarchy, women are not banned from the public sphere but face disparity and discrimination everywhere they go (paid work). By feminist movement, feminists tried to bring the essential changes from private to public patriarchy through the hardship to get access for giving vote, get permission to gain education, get the legal rights of property ownership, and get the right in marriage and divorce and so on. Though the famous concept about patriarchy is that, it is itself not defeated. Pollert (1996) argued, Walby's theory of patriarchy is the combination of two things which is clarification and description. However instead of detecting roots of patriarchy or Walby's theory tends towards discoid dispute where clarification for the method of patriarchy is mainly carry the meaning of attributes of patriarchy itself. So she aimed for conquering the weakness of patriarchy as an explanatory idea which is ineffective. She needs more detailed examination of patriarchy instead of an elucidation about why it exists or how it is sustained. So after knowing Walby's explanatory theory should be abandoned and instead of explanation, there is the need of description about the institutions where men dominate women. To sum up, the existence of patriarchy lies one of the predominant issues to explicate the process of gender development among different countries women and their roles after staying in a male dominated society where men are the bread winners.

\section{Notified Concept 'Power' to Determine Gender Development}

Power is enormously one of the complex matters. We can attempt a thumbnail sketch after studying the feminists and gender studies. The accurate meaning of power is to reach to the goals of whatever is desired even so if there is any opposition. Power may be expressed via the recognized legitimacy of those who grasp it. Since thirty years feminists did encapsulate the notion about how patriarchal power operates in the slogan. 'The personal is political', it says, as the state policy is not interfering in the home affairs which can conduct to the permitted male power such as domestic violence. According to Marxist, the state hold power in both the sections such as economic and ideological areas. But the feminists rejected all kinds of hierarchies regarding power in a structures less movement, where there will be no leaders and no subalterns, and everything need to be done on relation as well as with full agreement of whole group. In a more radical way power can be defined through the second wave feminism. Through this kind of concept it can be said that some feminist groups wanted to dismantle the power system which perpetuated such divisions. The some other embraced Foucault's theory on power. This model of power is based on the power which is exchanged between oppressors and oppressed. This model also suggests self-governance, panoptical model, in this model people, police, both of them will think or assume that they might be 
under surveillance. Foucault described how power challenges the monolithic notion of male power by using the panoptical model of power. Foucault suggest an innovative to consider power which is beyond incorporated by state or clan of people who could exercise the power at a microcosmic level.

\section{Violence upon Women in the Branch of Gender Development}

The definition of violence is both cultural and legal which do reflect the authority of some social associations who does keep the power to make their perspective. Therefore it take account of visible or meaningful is what or is not we call as violence. According to legal sense, unlawful physical force by the independents against others. The boarder address determines violence as "behavior which harms others, either physically or emotionally" (Pilcher \& Whelehan, 2004, P.173). According to Kelly and Radford (1998) the boarder conceptualization is the concept of the violence which got the endurance. Within the rage of harmful behavior that incorporated from physical acts of murder and rape to verbal acts of sexualized, radicalized abuse. Whether a limited or broader idea about violence which do remain as gendered. While on the other ways, it portrays the designs of variation between men and women, being especially connected with the behavior of men. Men's damaging behavior towards women, including rape, domestic violence and sexual harassment, and violence detected as the main mechanism in the subordination of women by men. Towards feminist researchers men's supremacy and authoritative attitudes for women got the especial concern. The embodiment of the subordinating effect of violence against women is showing that women are afraid about brutal attack than men, therefore this fear create effects in a huge way upon their freedom of activity outside the home. As Walklate (1995) mentioned about the practice and the temper of women's expression in which do intimidate, and often sexualized, often violent behavior of some men, which is not penalized as criminal activities. So we can say that the range of violence actually go to the excessive level of violence. Men's tortures against women ranged from sexualized vulgar observations to threat, unwanted physical contact and even attempt of sexual strike. As an aftermath of those tortures of men, women got severe fear of sickness, the sense of bullying and anger. Thus they feel they are the oppressed by men or male dominated society. Yet Kelly and Radford found that, frequently the importance of horrible experience by men upon women became minimized. There is a traditional saying for women which showed that they are the suppressed entities under male dominance. The family members take their issues lightly if any problem occur to them and say that 'but nothing actually happened' or 'nothing really happened'. In this way, Kelly and Radford discussed above words actually that shows the fact about women's obvious distress that enlarge the area of women's misfortune tortures and violence they experience regularly. While on the other hands men try to minimize the importance of their own abusive, threating and violating behavior. It was also explored that, men use a span of oratory devices to diminish the magnitude of their terrorizing behavior. Therefore it interpret as 'not violent' at all. In the male dominated society, people often try to minimize the grievous crimes of men upon women, for example at home they consider domestic violence actually occur because women is blamed for arousing anger in her aggressor, or in cases of repeated violence for not leaving him. In cases of rape, society give bad comments on women 
instead of giving punishment to the criminals. They say it happened because women are somehow responsible, for example, force to lead men on to a point where his sexual urge for having intercourse or for dressing temptingly. These are the examples of minimalizing men's crime upon women, they can do it because masculinities predominate over femininities within gender relations. But recently this normalization of men's aggressive behavior is increasingly challenged, repelled whether by individual women and men in their everyday experiences or by academic researchers, campaign groups and support organizations and professionals working within the criminal justice system. That means whatever outcome, there is always the influence of boosting masculinity.

\section{The Importance to Understand Gender Parity through the Study of Women's Studies in the Branch of Gender Development}

Women's studies included the branch of academic study during the appearance of feminism's second wave and a new branch of political activism. In 1960s in the USA and UK, some courses were included for adult and for higher education. In 1980s MA in women's studies has been offered at the University of Kent followed by others masters and undergraduate degrees elsewhere. Women's studies courses or modules have also expanded across Europe, Australia, Asia and Middle East. Women's studies actually established by the second wave feminists because they noticed women were frequently excluded from the society and to re-build their interests and identity this women studies got emerged. In the branch of gender development studies, women's studies become one of the important parts. It is not only operates as a critique of authentic knowledge, but it is also indicates the commitment to provide further analyses of women's lives. Therefore we can say through this field of area called women's studies, feminist theories did open vast possibility of the analysis and explanation of gender difference and its prolongation. Thus masculinity and male social roles might be of lawful review.

\section{Conclusion}

Gender and development (GAD), alludes to the development point of view and procedures which is eligible to do participate and empower the gender roles, also the status of it is equal, sustainable, free from anarchy, and respectful of human rights. This human rights actually refers to the Self-determination and actualization of human potentials. It also finds to acquire gender equitability as a basic value which should be reflected in the choices of development and elucidate that women are active of getting development, but not just passive receivers of development. The most general definition of gender symbolizes to an individual anatomical sex or sexual assignment, and also exhibit the cultural and social aspects of being male and female. An individual person's gender identity depend on his/ her personal sense of maleness and femaleness. The trace of gender role lies on the outward expression of identity according to the cultural and social expectations. Gender can stay out of a gender role like a man or a woman can be homemaker but for the matter of sex role, the gender role is limited anatomically. For instance, only woman can gestate and give birth while a man can't do that. Therefore it can be proclaim that gender development is the medium to evaluate the matter of gender inequality between men and women, especially how women are divesting from both 
the personal and private life. Such as at their home while on the other sides economically and politically, women are lagging behind which has been detected by the feminist theorists. Second wave feminism actually did introduce about how the issues of gender inequality got eliminated from academic disciplines, therefore they did pay the attention about how women's roles and identity were neglected and this thing occurred prior to the 1970s. So here it is the proof that since 1970s women were struggling to get their proper rights in every spheres of life. The social sciences also ignored this issue of gender in general while sociology did it in a larger ways. In pre 1970s gender blind sociology only highlighted women as wives and mothers within their families but at that time differences or inequalities between men and women were not seen or recognized as sociological awareness and problems to be noted. The differences and inequalities actually happened in 1970s and especially by women sociologists, therefore they felt the urgency or need to identify and took the initiatives to examine those problems. In English literature, women's worthiness got ignored and prohibited. That is why they were searching for their authority to get the general law of significant works of literature. The leadership of a norm about substantial works of literature that particularly prohibited women writers altogether and had nothing to say about the material and social conditions and prohibited the emergence of great women in this arena. To analyses in which arena women's worthiness of study in their own right arrived and to search the utmost success for feminist politics, scholars went beyond the ordinary boundaries of their home disciplines. Here I would like to mention Kate Millett's path finding sexual politics that progressed smoothly from literary criticism to a critique of Freud and Marx. Her perspectives later became extremely the business of literary studies. In 1960s and early 1970s total number of women were in the fields of humanities in comparison to other academic fields constructed this as an era that was fully developed for feminist critiques. Thus the existence of women were developed and the outcome of the gendered logic of the work place appeared. In late 1960s in US and from the mid to late 1970s in the UK that women's studies begun to evolve as a specialized sector of academic interest, also it was swiftly outspreaded around the globe. In UK British women's studies was emerged in MA program in Kent (1980), then York and Warwick. In those places and era women's studies was included as a diplomatic area of study. In US (1969) such courses like women's studies begun to be taught quite impulsively natural or careless way without considerable precedent organization in many US colleges and universities. So we can say it was a related story in the UK and retrospectively without considering any past situations. The teachers in the field did communicate both nationally and internationally. The first national women's studies conference took place in the UK in 1976. Scholars of women's studies were frequently found beyond the academy such as in the newsletters, at conferences and generally used to connect with same-minded thinkers. Their research on this women's studies proved that it is not only inspiring the boundaries of existing knowledge but also evolving new sectors of study as well as validating the conflict about cultural experiences of women. Therefore it has to be said that women were always in search of their identity both in private and working areas and in some areas they got success and in some areas still they are lagging behind than men. But the dynamic process of gender development can minimize the gender inequality between males and females. 


\section{Macrothink}

\section{References}

Banks, O. (1981). Faces of Feminism. Oxford: Martin Robertson.

Barrett, M., \& McIntosh, M. (1982). The Anti-social Family. London: Verso.

Barrett, M., \& Phillips, A. (Eds.). (1992). Destabilising Theory: Contemporary Feminist Debates. Cambridge: Polity Press.

Butler, J. (1999). Gender Trouble (2nd ed.). London: Routledge.

De Beauvoir, S. (1972). The Second Sex. Harmondsworth: Penguin Books.

Delphy, C., \& Leonard, D. (1992). Familiar Exploitation. Cambridge: Polity.

Echols, A. (1989). Daring to Be Bad: Radical Feminism in America 1967-1975. Minneapolis: University of Minnesota Press.

Gatens, M. (1996). Imaginary Bodies: Ethics, Power and Corporeality. London: Routledge.

Sawicki, J. (1991). Disciplining Foucault: Feminism, Power and the Body. London: Routledge.

Squires, J. (1999). Gender in Political Theory. Cambridge: Polity.

Twomey, B. (2002). Women in the Labour Market. Labour Market Trends, 110(3), 109-127.

\section{Copyright Disclaimer}

Copyright reserved by the author(s).

This article is an open-access article distributed under the terms and conditions of the Creative Commons Attribution license (http://creativecommons.org/licenses/by/3.0/). 